\title{
Synthesis and Photophysical Properties of Substituted
}

\section{Pyrimidines}

\author{
Sylvain Achelle ${ }^{1, *}$, Julián Rodríguez-López ${ }^{2,}$, ,Massinissa Larbani ${ }^{1}$, Rodrigo Plaza-Pedroche ${ }^{2}$ andFrançoise \\ Robin-le Guen ${ }^{1}$
}

1

Université de Rennes, CNRS, Institut des Sciences Chimiques de Rennes-UMR 6226, F 35000 Rennes, France 2

Área de Química Orgánica, Facultad de Ciencias y Tecnologías Químicas, Universidad de Castilla-La-Mancha, Avda. Camillo José Cela 10, 13071 Ciudad Real, Spain

Authors to whom correspondence should be addressed.

Academic Editor: Frédéric Paul

Received: 11 April 2019 / Accepted: 3 May 2019 / Published: 5 May 2019

\begin{abstract}
A series of pyrimidine derivatives bearing one, two or three triphenylamine/9-ethylcarbazole substituents has been synthesized by Suzuki cross-coupling reaction. All compounds showed absorption bands in the UV region and the emission of violet-blue light upon irradiation. Protonation led to quenching of the fluorescence, although some derivatives remained luminescent with the appearance of a new red-shifted band in the spectra. Accurate control of the amount of acid enabled white photoluminescence to be obtained both in solution and in solid state.
\end{abstract}

\section{Keywords:}

pyrimidines; fluorescence; white-light emission; intramolecular charge transfer

\section{Introduction}

The pyrimidine (1,3-diazine) core is a $\pi$-deficient six-membered heterocycle with two nitrogen atoms. Consequently, the pyrimidin-4-yl and the pyrimidin-2-yl fragments act as relatively strong electron-withdrawing groups [1]. With regard to pyridyl analogues, the presence of an appropriately positioned second nitrogen atom significantly enhances their electron-attracting character [2]. The pyrimidine ring has therefore been extensively used as an acceptor unit in push-pull structures in which significant intramolecular charge transfer (ICT) occurs $[1,3,4]$. In this respect, 4,6-di(arylvinyl)pyrimidines are now well established two-photon absorption chromophores for biological imaging [5,6,7,8], 3D lithographic microfabrication [9], and 3D data storage [10]. Appropriately substituted 2,4,6-triarylpyrimidines have also been developed as efficient emitters for OLEDs due to their thermally activated delayed fluorescence (TADF) properties $[11,12,13,14,15]$. Pyrimidine push-pull chromophores have also been developed as second order nonlinear optic (NLO) materials $[16,17]$ and as dyes for photovoltaic applications $[18,19]$.

When compared to their arylvinyl- and arylethynyl- analogues, arylpyrimidines generally exhibit a blue-shifted emission with a higher emission quantum yield $[1,20]$. Arylpyrimidines can be easily obtained by Suzuki crosscoupling reaction from halogenopyrimidines $[21,22,23,24]$. The electron-withdrawing character of the pyrimidinyl fragments allows this reaction to be performed from chloro-derivatives [25].

The emission properties of pyrimidine fluorophores are highly sensitive to the environment. As a consequence, a strong emission solvatochromism, which is typical of ICT chromophores [26,27,28,29], is observed: a polarity increase provides a significant bathochromic shift of the emission band [30,31,32,33]. On the other hand, protonation of the pyrimidine ring $\left(\mathrm{pK}_{\mathrm{a} 1}=1.1\right)$ significantly enhances its electron-withdrawing character and leads to a red-shift of both absorption and emission bands. These shifts are generally accompanied by emission quenching, but in some cases, particularly with weak electron-donating groups such as methoxy fragments, red-shifted emission with increased intensity is observed $[32,34,35]$. White photoluminescence can be 
obtained both in solution and in doped polystyrene films when the neutral and protonated forms are present in the appropriate ratio $[34,35]$.

Triphenylamine and 9-ethylcarbazole have been extensively used as electron-donating units in push-pull structures [36,37,38,39]. Although these units are weaker electron-donors than $N, N$-dialkylanilines [40], derivatives that incorporate these moieties generally have stronger luminescence properties $[41,42,43]$. Nevertheless, only a few pyrimidine derivatives bearing triphenylamine or 9-ethylcarbazole fragments have been described in the literature $[9,19,44,45]$.

We report here the synthesis of a series of pyrimidine chromophores with one, two or three triphenylamine/9ethylcarbazole substituents. The photophysical properties of the new materials were carefully studied and the luminescence behaviour in the presence of acid was evaluated. In some cases, the protonated pyrimidines remained emissive, which enabled white luminescence to be obtained by accurate control of the amount of acid.

\section{Results and Discussion}

\subsection{Synthesis}

Compounds 1 and $\mathbf{2}$ were obtained in moderate to good yield by Suzuki cross-coupling reaction from the corresponding chloropyrimidines and boronic acids according to a known methodology for similar pyrimidine structures (Scheme 1) $[21,22,23,24]$. All compounds were identified by ${ }^{1} \mathrm{H}$ and ${ }^{13} \mathrm{C}-\mathrm{NMR}$, and all previously unknown molecules were also characterized by high resolution mass spectroscopy (HRMS).

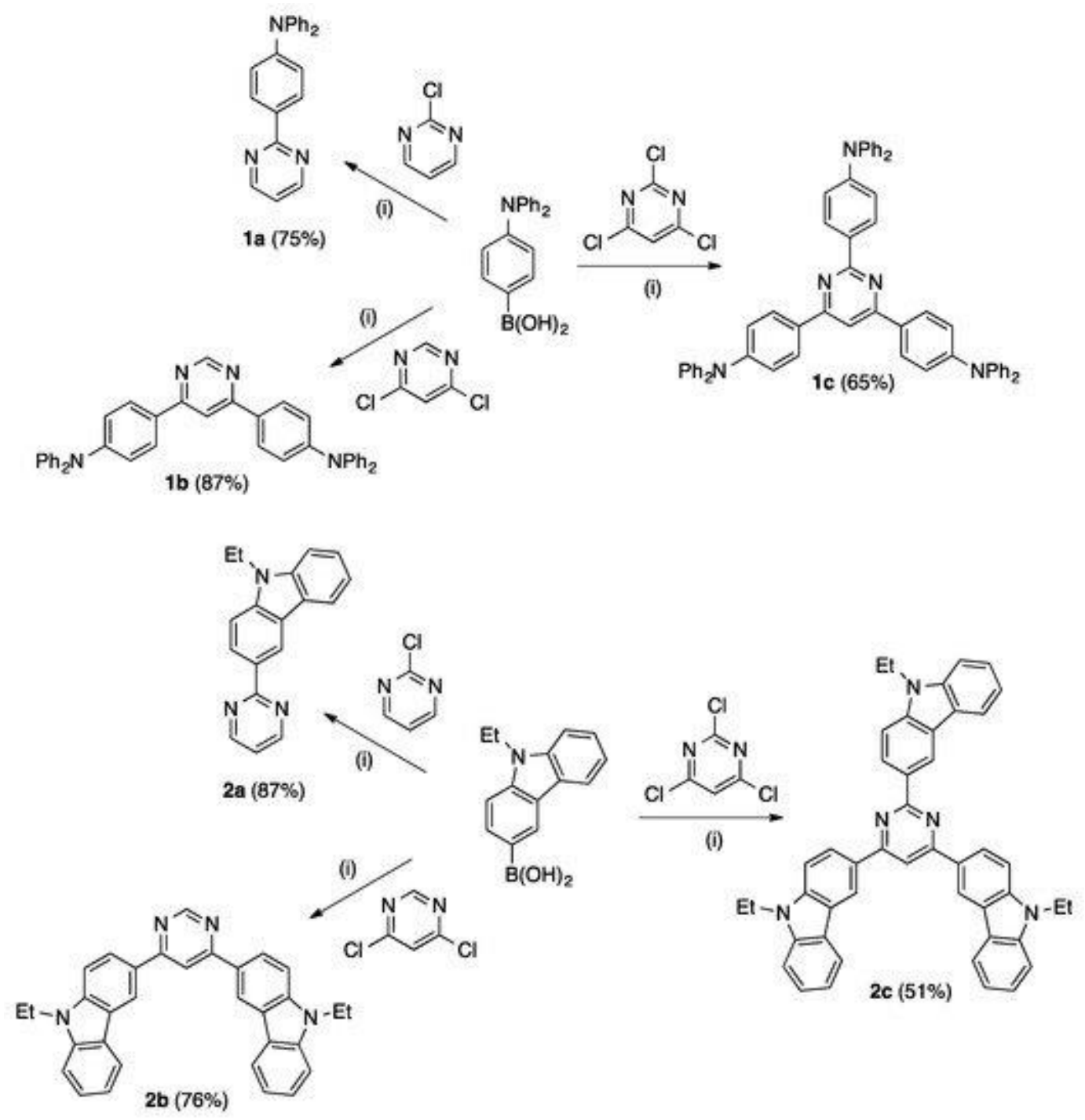

Scheme 1. Preparation of pyrimidines 1 and 2. (i) Toluene, $\mathrm{Pd}\left(\mathrm{PPh}_{3}\right)_{4}, \mathrm{Na}_{2} \mathrm{CO}_{3}$ aq., $\mathrm{EtOH}, \Delta, 15 \mathrm{~h}$.

\subsection{Photophysical Properties in Solution}

The UV-Vis and photoluminescence (PL) spectroscopic data for compounds $\mathbf{1}$ and $\mathbf{2}$ in dichloromethane are presented in Table 1. The analyses were carried out using low concentration solutions $\left(1.0-2.0 \times 10^{-5} \mathrm{M}\right)$. Self- 
absorption effects were not observed under the conditions employed. As representative examples, the spectra of compounds 1a-c are shown in Figure 1 (see Figure $\mathrm{S} 1$ in the Supporting Information for spectra of compounds $2 \mathrm{a}-\mathbf{c})$.

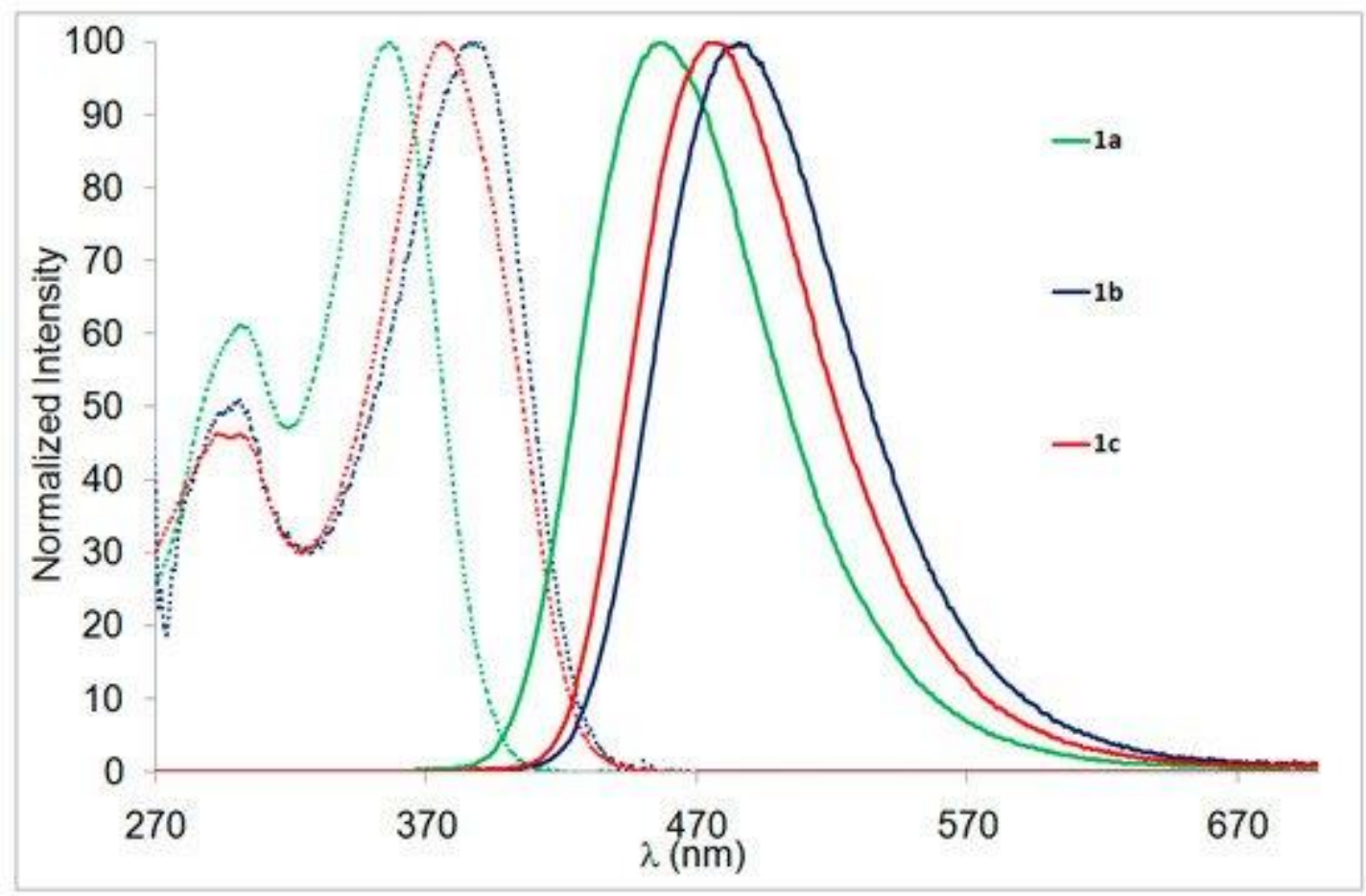

Figure 1. Normalized absorption (dashed lines) and emission (solid lines) spectra of compounds $\mathbf{1 a}$ (green), $\mathbf{1 b}$ (blue) and 1c (red) in dichloromethane solution.

Table 1. UV-Vis and photoluminescence (PL) data for compounds 1 and 2 in $\mathrm{CH}_{2} \mathrm{Cl}_{2}$ solution.

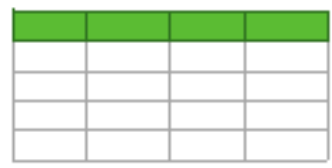

Compounds 1, which contain triphenylamine substituents, exhibited red-shifted absorption and emission bands with respect to their 9-ethylcarbazole analogues 2 . This finding indicates that the 9 -ethyl-9H-carbazol-3-yl fragment is a weaker electron-donating group than triphenylamine. Triphenylamine derivatives 1 also displayed higher fluorescence quantum yields (up to 0.86 for $\mathbf{1 b}$ ). The 4,6-disubstituted pyrimidines $\mathbf{1 b}$ and $\mathbf{2 b s h o w e d ~ a ~}$ red-shifted emission and an enhanced fluorescence quantum yield in comparison with their C2-monosubstituted analogues $\mathbf{1} \mathbf{a}$ and $\mathbf{2} \mathbf{a}$. In contrast, the addition of a third substituent (2,4,6-triarylpyrimidines) led to a slight blue shift in the emission and a decrease in the quantum yield. A similar phenomenon has previously been observed in tristyrylpyrimidines and was attributed to a decrease in the electron-withdrawing character of the pyrimidine central core due to the C2 electron-donating substituent, which decreases the ICT along the C4 and C6 arms [32].

In an effort to gain further insights into the photophysical properties of these push-pull molecules, in particular to evaluate the ICT upon excitation, the emission behaviour of compounds 1 and $\mathbf{2}$ was studied in a variety of different aprotic solvents. The data obtained are summarized in Table 2. The position of the longest wavelength absorption maximum was not affected significantly but an increase in the solvent polarity, estimated by the Dimroth-Reichardt polarity parameters [46,47], resulted in a red-shifted emission (see Figure 2 for compound $\mathbf{1 b}$ and Figures S2-S6 in the Supporting Information for compounds 1a, 1c, and 2a-c). This bathochromic shift in the emission band is consistent with stabilization of the highly polar emitting excited state by polar solvents. The solvatochromic shift of the emission band can be used to evaluate the ICT upon excitation. For all compounds, the emission maxima were plotted versus the Dimroth-Reichardt polarity parameter, and in all cases good linearity was found (see Figure S7 in the Supporting Information). The slopes of the corresponding regression lines indicate a stronger ICT for triphenylamine derivatives 1 with respect to their 9-ethylcarbazole 
analogues 2. In the triphenylamine series, the slope increased in the order $1 \mathbf{a}<\mathbf{1 c}<\mathbf{1 b}$, thus indicating that the strongest ICT was obtained for the 4,6-disubstituted pyrimidine $\mathbf{1 b}$. In a similar way, the slope increased in the order $\mathbf{2} \mathbf{a}<\mathbf{2} \mathbf{c}<\mathbf{2} \mathbf{b}$ for the 9-ethylcarbazole derivatives.

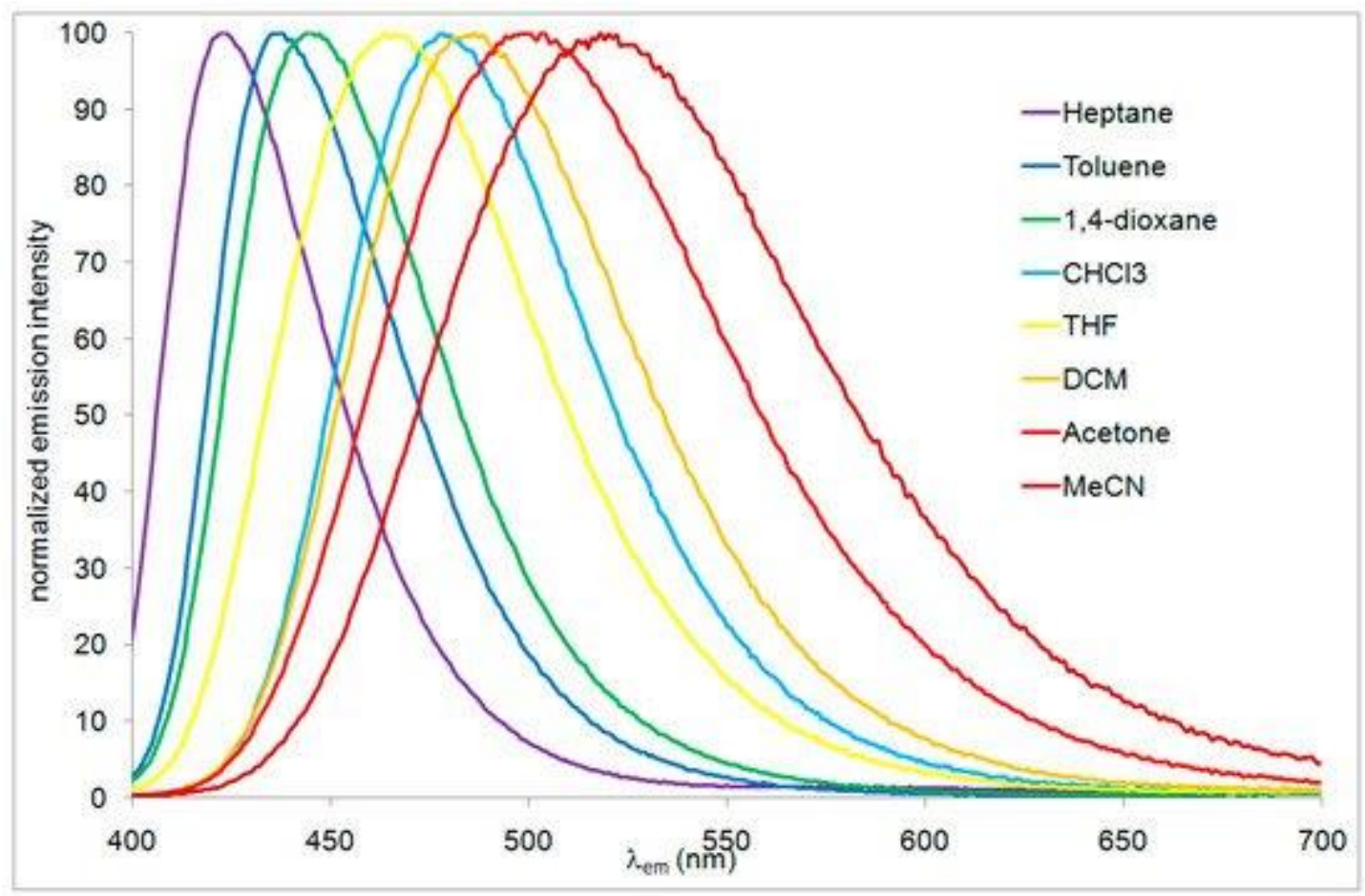

Figure 2. Normalized emission spectra of $\mathbf{1 b}$ in different aprotic solvents.

Table 2. Emission solvatochromism of compounds 1 and $\mathbf{2}$ in various aprotic solvents.

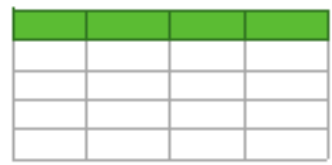

Photophysical measurements were also performed on a $10^{-2} \mathrm{M}$ solution of camphorsulfonic acid (CSA) in dichloromethane. The results are summarized in Table 3. As one would expect, a bathochromic shift of the charge transfer absorption band was observed for all compounds due to the protonation of the pyrimidine ring $[45,48]$. This was associated with a dramatic quenching of the fluorescence for the triphenylamine derivatives. As a consequence, emission bands could not be identified for compounds $1 \mathrm{a}$ and $\mathbf{1 c}$, whereas for $\mathbf{1 b}$ a low intensity emission in the red region was detected $\left(\lambda_{\max }=651 \mathrm{~nm}, \Phi_{\mathrm{F}}<0.01\right)$. It is worth noting that the protonated form of $1 \mathbf{b}$ was more emissive in chloroform solution ( $\left.\lambda_{\mathrm{abs}}=493 \mathrm{~nm}, \lambda_{\mathrm{em}}=625 \mathrm{~nm}, \Phi_{\mathrm{F}}=0.11\right)$. In contrast, the 9-ethylcarbazole derivatives $\mathbf{2 b}$ and $\mathbf{2 c}$ remained fluorescent and they emitted green-yellow light with high emission quantum yields ( $\Phi_{F}=0.63$ and 0.45 , respectively). The decay lifetimes $(T)$ were determined to be $3.6 \mathrm{~ns}$ and $4.2 \mathrm{~ns}$ (T values for the neutral molecules were $1.8 \mathrm{~ns}$ and $1.7 \mathrm{~ns}$, respectively).

Surprisingly, $\mathbf{2 a}$ was not emissive in acidified dichloromethane. The effect of protonation was studied in a more detailed way by titration of solutions of compounds $\mathbf{1 b}, \mathbf{2} \mathbf{b}$ and $\mathbf{2 c}$ with CSA. The changes observed in the UVvis and emission spectra for $\mathbf{2} \mathbf{b}$ are illustrated in Figure 3 and Figure 4 , respectively (see the Supporting Information for data for compounds $\mathbf{1 b}$ and $\mathbf{2 c}$ ). The absorption spectra showed the progressive disappearance of the charge transfer absorption band of the neutral form, whereas a red-shifted charge transfer absorption band for the protonated form progressively appeared. The presence of an isosbestic point is evident and this is characteristic of an equilibrium between two species (Figure 3). The same trend was observed in the emission spectra: the addition of CSA led to the progressive disappearance of the emission band of the neutral form and this was associated with the enhancement of a new red-shifted band corresponding to the emission of the protonated form with an isoemissive point (Figure 4). 


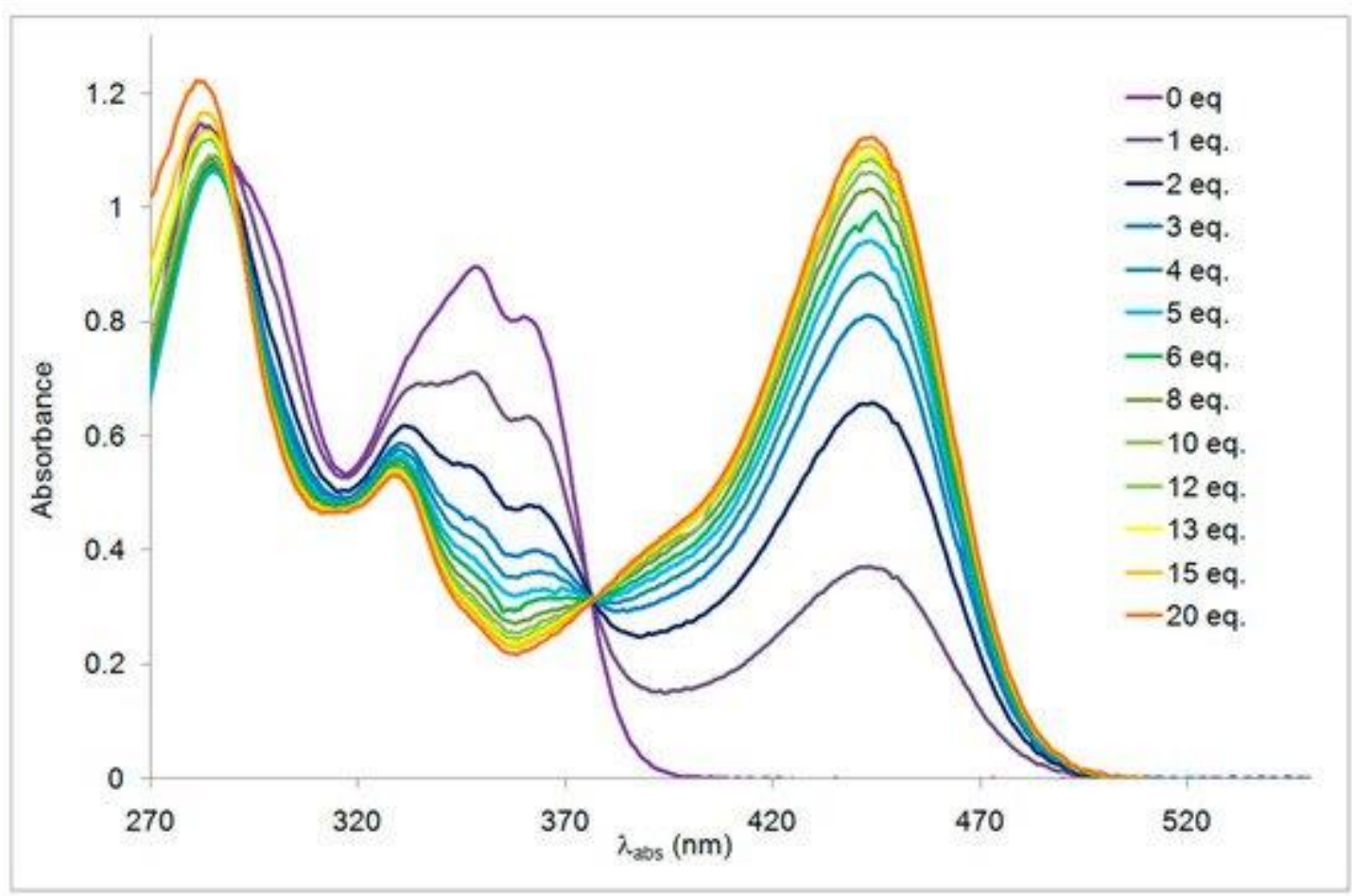

Figure 3. Changes in the absorption spectra of a dichloromethane solution of $2 \mathbf{b}\left(c=1.87 \times 10^{-5} \mathrm{M}\right)$ upon addition of CSA (0-20 equivalents).

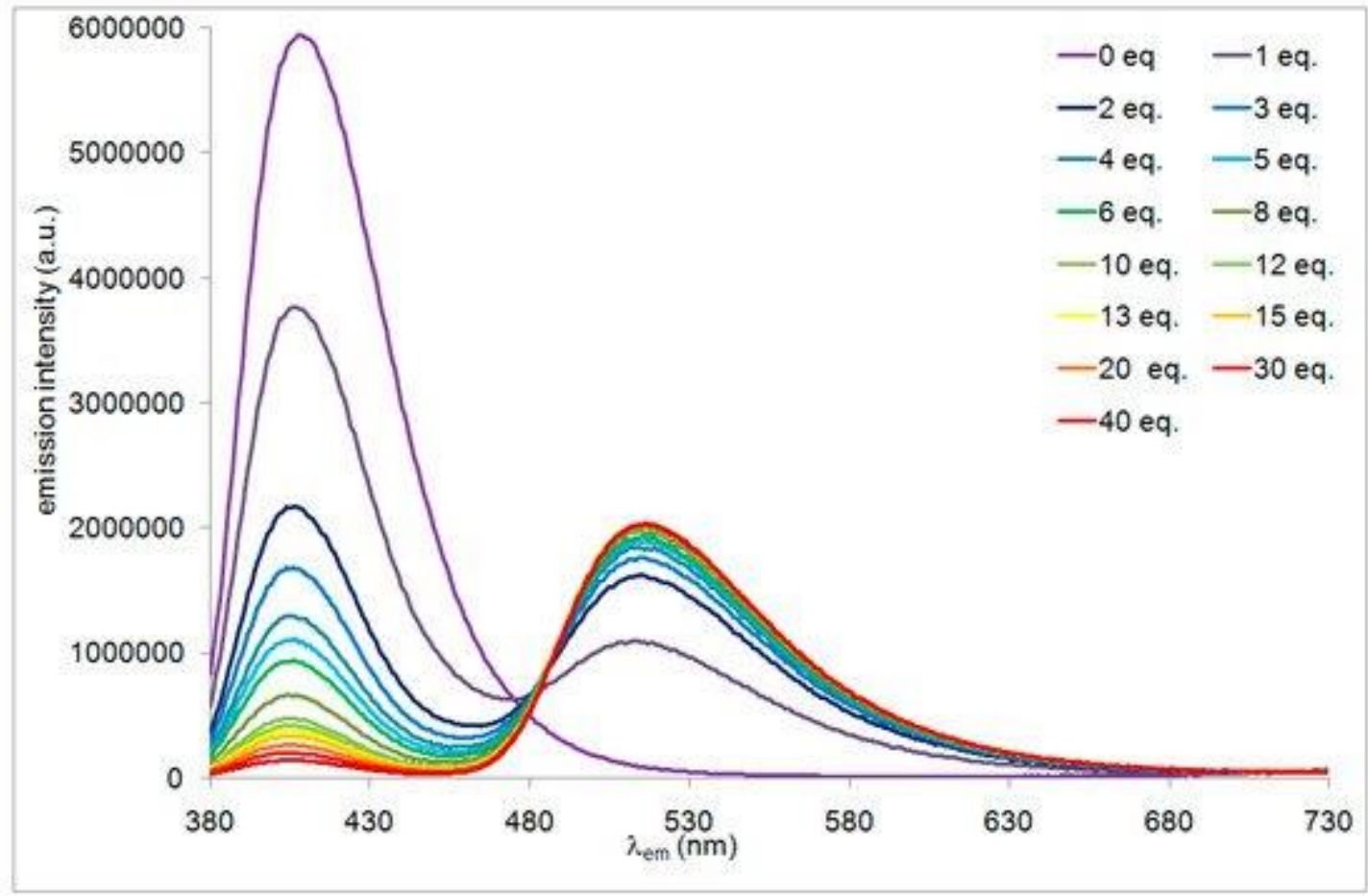

Figure 4. Changes in the emission spectra of a dichloromethane solution of $\mathbf{2 b}\left(c=1.97 \times 10^{-5} \mathrm{M}\right)$ upon addition of CSA (0-40 equivalents), $\lambda_{\mathrm{exc}}=370 \mathrm{~nm}$.

Table 3. UV/Vis and PL data for compounds 1 and 2 in acid solution $\left(10^{-2} \mathrm{M} \mathrm{CSA}\right.$ in $\left.\mathrm{CH}_{2} \mathrm{Cl}_{2}\right)$.

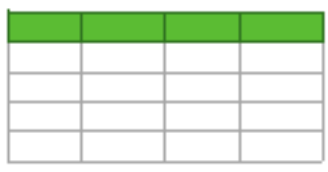

The coexistence of both neutral and protonated species with complementary emitting colors in the solution enabled white light emission to be achieved under UV-irradiation. Thus, compound $\mathbf{2 c}$ emitted violet light at $\lambda_{\max }=398 \mathrm{~nm}$ and this turned to green-yellow at $\lambda_{\max }=552 \mathrm{~nm}$ upon protonation. Excitation at $370 \mathrm{~nm}$ led to the observation of white light after the addition of 45 equivalents of CSA to a $1.25 \times 10^{-5} \mathrm{M}$ solution of $2 \mathrm{c}$ in 
dichloromethane (Figure 5). The same phenomenon was also observed for compounds $\mathbf{1 b}$ and $\mathbf{2 b}$ (Figures S11 and S12 of the Supporting Information, respectively). For $\mathbf{1 b}$ and $\mathbf{2 c}$, the calculated CIE chromaticity coordinates (Table 4) were close to those of pure white light $(0.33,0.33)$.

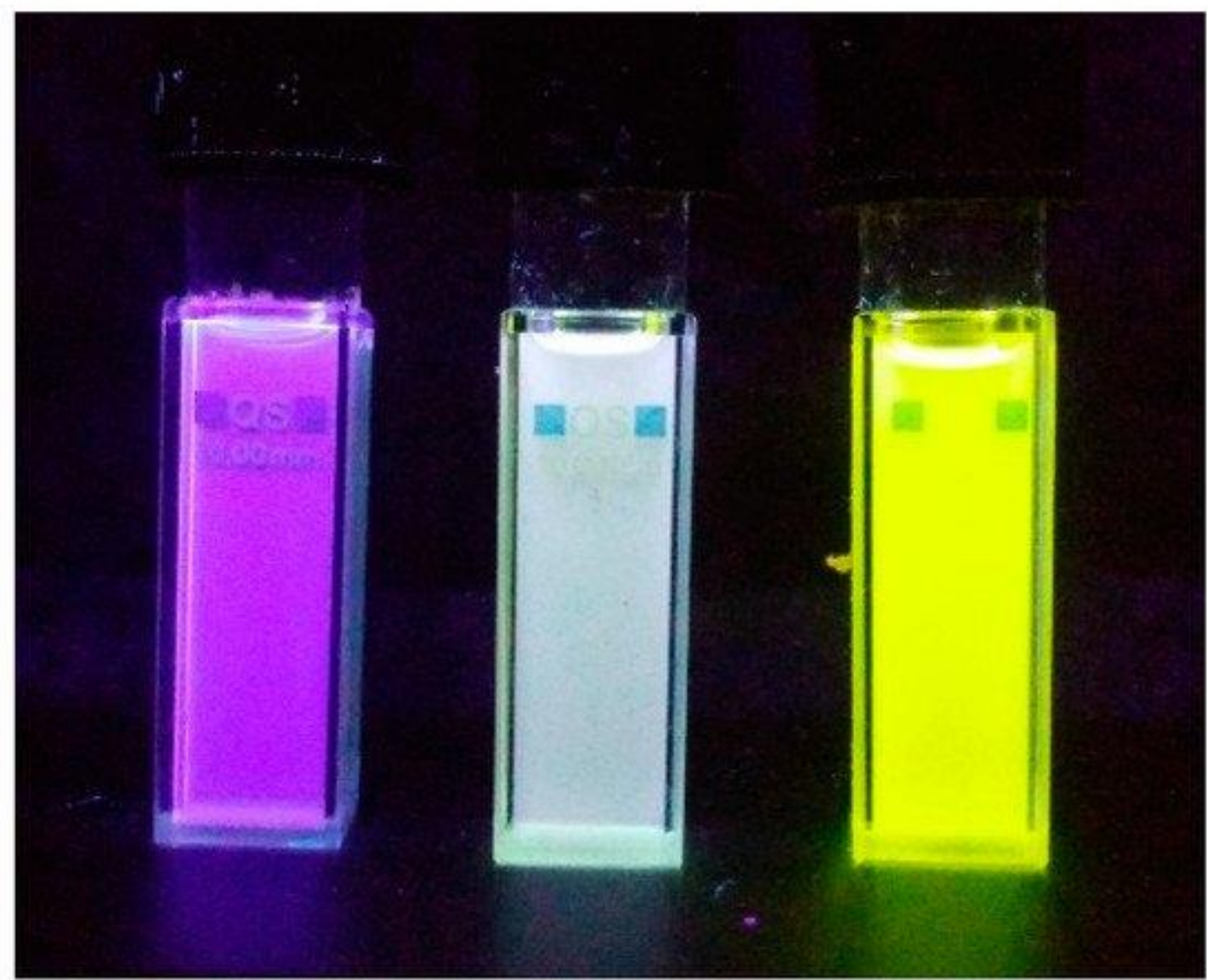

Figure 5. Changes in the color of a dichloromethane solution of $2 \mathrm{c}\left(c=1.25 \times 10^{-5} \mathrm{M}\right)$ after the addition of 45 equivalents (middle) and in 10-2 M CSA (right). Photographs were taken in the dark upon irradiation with a handheld UV lamp $\left(\lambda_{\mathrm{em}}=366 \mathrm{~nm}\right)$.

Table 4. CIE coordinates for compounds 1 and 2 in solution.

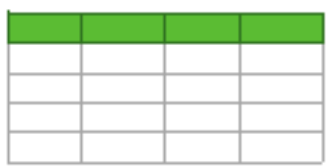

\subsection{Photophysical Properties in Solid State}

Filter paper pieces covered with $\mathbf{2} \mathbf{b}$ and $\mathbf{2} \mathbf{c}$ in the absence and presence of different amounts of CSA were prepared by immersion of the filter paper into a dichloromethane solution of the appropriate compound (1 wt\% doped on polystyrene). The samples were dried in air. The fluorescence spectra of the samples were acquired and emission maxima in the violet region at $\lambda_{\max }=405 \mathrm{~nm}$ and $406 \mathrm{~nm}$, respectively, were determined in the absence of acid. The intensities of these bands gradually decreased on increasing the amount of CSA, whereas a distinctly novel enhanced emission appeared in the green-yellow region ( $\lambda_{\max }=544 \mathrm{~nm}$ for $\mathbf{2 b}$ and $\lambda_{\max }=554$ $\mathrm{nm}$ for $\mathbf{2 c}$ ). After careful tuning of the number of equivalents of CSA, white light was observed due to the simultaneous emission from both the neutral and protonated compounds. These significant emission changes were easily followed by the naked eye under UV irradiation (Figure 6 and Figure S13 in the Supporting Information). Energy transfer between neutral and protonated molecules has been suggested for related systems [49]. 

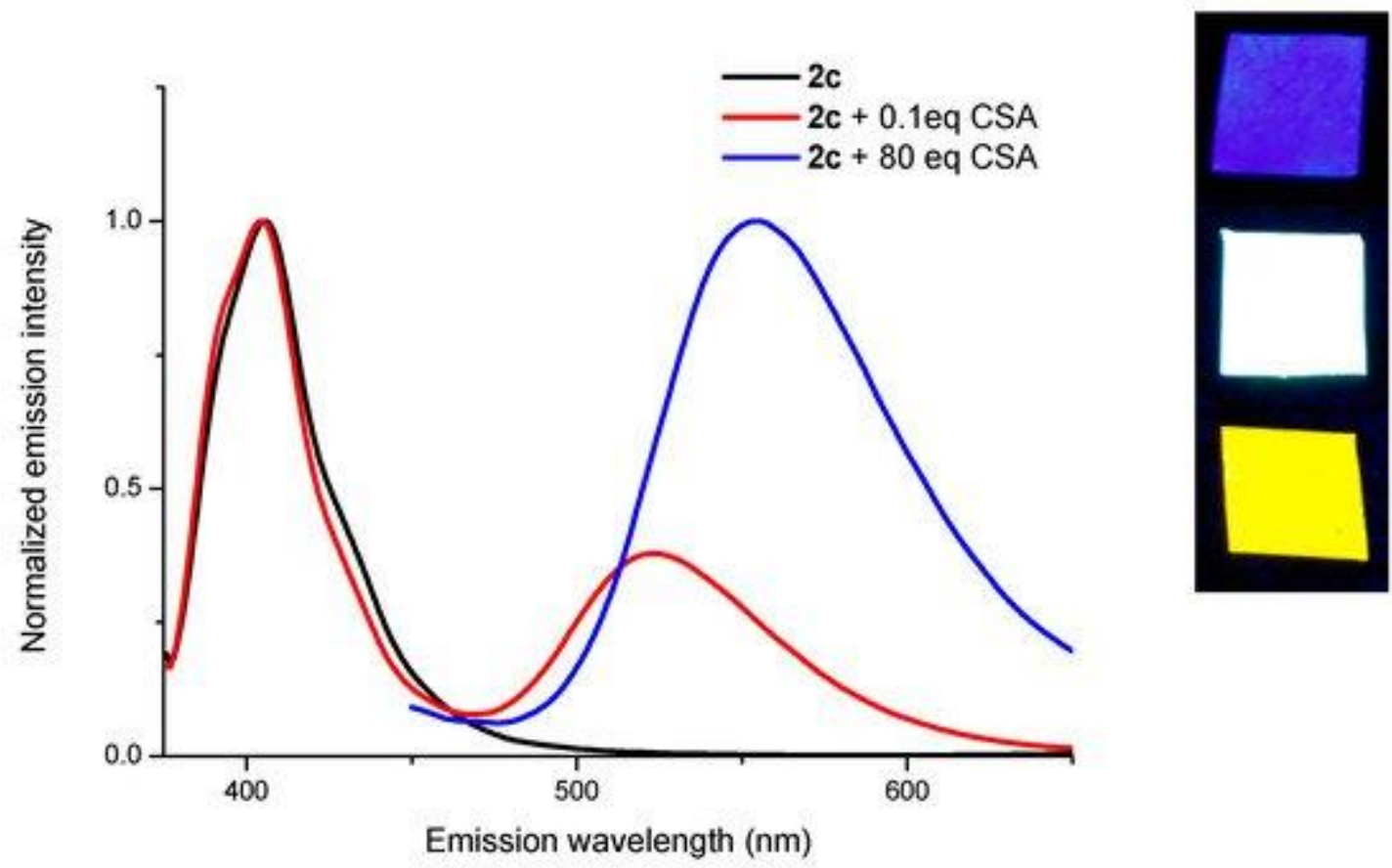

Figure 6. Fluorescence spectra $\left(\lambda_{\mathrm{exc}}=365 \mathrm{~nm}\right)$ and changes in the colour of filter paper samples after immersion into a dichloromethane solution of polystyrene doped with $2 \mathrm{c}(1 \mathrm{wt} \%)$ in the absence (top) and presence of 0.1 equivalents (middle) and 80 equivalents (bottom) of CSA. Photographs were taken in the dark upon irradiation with a hand-held UV lamp $\left(\lambda_{\mathrm{em}}=366 \mathrm{~nm}\right)$.

\section{Materials and Methods}

\subsection{General Information}

All solvents were reagent grade for synthesis and spectroscopic grade for photophysical measurements. The starting materials were purchased from Sigma-Aldrich (St Louis, MO, USA) or Alfa Aesar (Haverhill, MA, USA) and were used without further purification. For air- and moisture-sensitive reactions, all glassware was flame-dried and cooled under nitrogen. NMR spectra were recorded in $\mathrm{CDCl}_{3}$ on a Bruker Avance 300 spectrometer $\left({ }^{1} \mathrm{H}\right.$ at $300 \mathrm{MHz}$ and ${ }^{13} \mathrm{C}$ at $75 \mathrm{MHz}$, Billerica, MA, USA). The chemical shifts $\delta$ are reported in ppm and are referenced to the residual protons of the deuterated solvent or carbon nuclei $\left({ }^{1} \mathrm{H}, \delta=7.27 \mathrm{ppm} ;{ }^{13} \mathrm{C}, \delta=77.0 \mathrm{ppm}\right)$. The coupling constants $J$ are given in $\mathrm{Hz}$. In the ${ }^{1} \mathrm{H}-\mathrm{NMR}$ spectra, the following abbreviations are used to describe the peak patterns: s (singlet), d (doublet), dd (doublet of doublets), $t$ (triplet), $m$ (multiplet). In the ${ }^{13} \mathrm{C}-\mathrm{NMR}$ spectra, the nature of the carbons $\left(\mathrm{C}, \mathrm{CH}, \mathrm{CH}_{2}\right.$ or $\left.\mathrm{CH}_{3}\right)$ was determined by performing a JMOD experiment. Melting points $\left({ }^{\circ} \mathrm{C}\right)$ were measured on a Kofler hot-stage with a precision of 2 degrees $\left( \pm 2{ }^{\circ} \mathrm{C}\right)$. High-resolution mass analyses were performed at the 'Centre Régional de Mesures Physiques de l'Ouest' (CRMPO, Université de Rennes 1 , Rennes, France) using a Bruker MicroTOF-Q II apparatus. Analytical thin layer chromatography (TLC) was performed on 60 F254 silica gel plates (Merck, Darmstadt, Germany), and compounds were visualized by irradiation with UV light at 254 and $365 \mathrm{~nm}$. Flash chromatography was performed using silica SI 60 (60-200 mesh ASTM, Acros, Waltham, MA, USA). UV-visible and fluorescence spectroscopy studies were conducted on a Spex Fluoromax-3 spectrophotometer (Jobin-Yvon Horiba, Kyoto, Japan). Compounds were excited at their absorption maxima (band of lowest energy) to record the emission spectra. All solutions were measured with optical densities below 0.1 . Fluorescence quantum yields $( \pm 10 \%)$ were determined relative to 9,10 -bis(phenylethynyl)anthracene in cyclohexane $\left(\Phi_{\mathrm{F}}=1.00\right)$. Stokes shifts were calculated considering the lowest energetic absorption band.

\subsection{General Procedure for Suzuki Cross-coupling Reactions}

A stirred mixture of the chloropyrimidine derivative $(1 \mathrm{mmol})$, arylboronic acid (1.2 mmol per chlorine atom), $\mathrm{Pd}\left(\mathrm{PPh}_{3}\right)_{4}(0.05 \mathrm{mmol}$ per chlorine atom), $1 \mathrm{M}$ aqueous sodium carbonate (1.2 mmol, $1.2 \mathrm{~mL}$ per chlorine atom), and ethanol $(1.5 \mathrm{~mL})$ in degassed toluene $(15 \mathrm{~mL})$ was heated at reflux under nitrogen for $15 \mathrm{~h}$ in a Schlenk tube. The reaction mixture was cooled, filtered, and dissolved with a mixture of AcOEt and water 1:1 (50 mL) and the organic layer was separated. The aqueous layer was extracted with AcOEt $(2 \times 25 \mathrm{~mL})$. The combined organic 
extracts were dried with $\mathrm{MgSO}_{4}$ and the solvents were evaporated.

2-(4-Diphenylaminophenyl)pyrimidine (1a). The title compound was obtained according to the general procedure and purified by column chromatography $\left(\mathrm{SiO}_{2}\right.$, AcOEt/petroleum ether, 3:7). Beige solid. Yield: $75 \%$ (241 mg). Mp: 173-174 ${ }^{\circ} \mathrm{C}$ (lit.: 168-169 ${ }^{\circ} \mathrm{C}$ ) [50]. ${ }^{1} \mathrm{H}-\mathrm{NMR}\left(300 \mathrm{MHz}, \mathrm{CDCl}_{3}\right)$ : $\delta$ 7.17-7.05 (m, 9H), 7.31-7.27 (m, $4 \mathrm{H}), 8.28$ (d, $2 \mathrm{H}, J=9.0 \mathrm{~Hz}), 8.74$ (d, $2 \mathrm{H}, J=4.8 \mathrm{~Hz}) .{ }^{13} \mathrm{C}-\mathrm{NMR}\left(75 \mathrm{MHz}, \mathrm{CDCl}_{3}\right): \delta$ 118.2, 122.1, 123.6, 125.2, $129.2,129.4,130.9,147.3,150.3,157.1,164.5$.

4,6-bis(4-Diphenylaminophenyl)pyrimidine (1b). The title compound was obtained according to the general procedure and purified by column chromatography $\left(\mathrm{SiO}_{2}\right.$, AcOEt/petroleum ether, 3:7). Yellow solid. Yield: 87\% (492 mg). Mp: 230-231 ${ }^{\circ} \mathrm{C} .{ }^{1} \mathrm{H}-\mathrm{NMR}\left(300 \mathrm{MHz}, \mathrm{CDCl}_{3}\right): \delta 7.17-7.07(\mathrm{~m}, 16 \mathrm{H}), 7.33-7.27(\mathrm{~m}, 8 \mathrm{H}), 7.93(\mathrm{~d}, 1 \mathrm{H}, \mathrm{J}=$ $1.2 \mathrm{~Hz}), 7.99(\mathrm{~d}, 4 \mathrm{H}, J=9.0 \mathrm{~Hz}), 9.17(\mathrm{~d}, 1 \mathrm{H}, J=1.2 \mathrm{~Hz}) .{ }^{13} \mathrm{C}-\mathrm{NMR}\left(75 \mathrm{MHz}, \mathrm{CDCl}_{3}\right): \delta$ 110.9, 122.0, 123.9, 125.3, 128.1, 129.5, 129.9, 147.1, 150.4, 159.0, 163.7. HRMS (ESI/ASAP), m/zcalculated for $\mathrm{C}_{40} \mathrm{H}_{31} \mathrm{~N}_{4}[\mathrm{M}+\mathrm{H}]^{+} 567.2543$, found 567.2546 .

2,4,6-tris(4-Diphenylaminophenyl)pyrimidine (1c). The title compound was obtained according to the general procedure and purified by column chromatography $\left(\mathrm{SiO}_{2}\right.$, AcOEt/petroleum ether, 3:7). Yellow solid. Yield: $65 \%$ (526 mg). Mp: >260 C. ${ }^{1} \mathrm{H}-\mathrm{NMR}\left(300 \mathrm{MHz}, \mathrm{CDCl}_{3}\right)$ : $\delta 7.11-7.06(\mathrm{~m}, 6 \mathrm{H}), 7.18-7.15(\mathrm{~m}, 18 \mathrm{H}), 7.32-7.27(\mathrm{~m}, 12 \mathrm{H})$, $7.78(\mathrm{~s}, 1 \mathrm{H}), 8.11(\mathrm{~d}, 4 \mathrm{H}, \mathrm{J}=8.7 \mathrm{~Hz}), 8.51$ (d, 2H, J = 8.7 Hz). ${ }^{13} \mathrm{C}-\mathrm{NMR}\left(75 \mathrm{MHz}, \mathrm{CDCl}_{3}\right): \delta$ 107.9, 122.2, 122.4, 123.3, 123.7, 124.9, 125.2, 128.1, 129.3, 129.4, 130.8, 132.1, 147.2, 147.4, 149.9, 150.2, 163.7, 164.0 HRMS (ESI/ASAP), $\mathrm{m} / \mathrm{z}$ calculated for $\mathrm{C}_{58} \mathrm{H}_{44} \mathrm{~N}_{5}[\mathrm{M}+\mathrm{H}]^{+} 810.3591$, found 810.3591 .

2-(9-Ethyl-9H-carbazol-3-yl)pyrimidine (2a). The title compound was obtained according to the general procedure and purified by column chromatography $\left(\mathrm{SiO}_{2}\right.$, AcOEt/petroleum ether, 3:7). Beige solid. Yield: $87 \%$ (238 mg). Mp: 136-137 ${ }^{\circ} \mathrm{C}$. ${ }^{1} \mathrm{H}-\mathrm{NMR}\left(300 \mathrm{MHz}, \mathrm{CDCl}_{3}\right.$ ): $\delta 1.47$ (t, 3H, J = 7.2 Hz), 4.41 (q, $\left.6 \mathrm{H}, J=7.2 \mathrm{~Hz}\right), 7.14$ $(\mathrm{t}, 1 \mathrm{H}, J=4.8 \mathrm{~Hz}), 7.30-7.27(\mathrm{~m}, 1 \mathrm{H}), 7.52-7.42(\mathrm{~m}, 3 \mathrm{H}), 8.22(\mathrm{~d}, 1 \mathrm{H}, J=7.8 \mathrm{~Hz}), 8.61(\mathrm{~d}, 1 \mathrm{H}, J=7.8 \mathrm{~Hz}), 8.82$ (d, $2 \mathrm{H}, J=5.1 \mathrm{~Hz}), 9.22(\mathrm{~s}, 2 \mathrm{H}) .{ }^{13} \mathrm{C}-\mathrm{NMR}\left(75 \mathrm{MHz}, \mathrm{CDCl}_{3}\right): \delta$ 13.9, 37.7, 108.4, 108.7, 118.1, 119.5, 120.8, 121.0, 123.3, 123.5, 126.0, 126.2, 128.6, 140.6, 141.8, 157.2, 165.6. HRMS (ESI/ASAP), m/zcalculated for $\mathrm{C}_{18} \mathrm{H}_{16} \mathrm{~N}_{3}[\mathrm{M}$ $+\mathrm{H}]^{+} 274.1338$, found 274.1343 .

4,6-bis(9-Ethyl-9H-carbazol-3-yl)pyrimidine (2b). The title compound was obtained according to the general procedure and purified by column chromatography $\left(\mathrm{SiO}_{2}, \mathrm{AcOEt} /\right.$ petroleum ether, 1:1). Pale yellow solid. Yield: $76 \%$ (352 mg). Mp: $170-171^{\circ} \mathrm{C}$ (lit.: $176-177^{\circ} \mathrm{C}$ ) [45]. ${ }^{1} \mathrm{H}-\mathrm{NMR}\left(300 \mathrm{MHz}, \mathrm{CDCl}_{3}\right): \delta 1.45$ (t, $\left.6 \mathrm{H}, \mathrm{J}=6.9 \mathrm{~Hz}\right), 4.33$ (q, $4 \mathrm{H}, J=6.9 \mathrm{~Hz}$ ), 7.53-7.30 (m, 8H), 8.32-8.24 (m, 5H), $8.99(\mathrm{~s}, 2 \mathrm{H}), 9.36(\mathrm{~s}, 1 \mathrm{H}) .{ }^{13} \mathrm{C}-\mathrm{NMR}\left(75 \mathrm{MHz}, \mathrm{CDCl}_{3}\right)$ : $\delta 13.8,37.7,108.6,108.8,111.5,119.6,119.7,120.8,123.2,123.5,124.9,126.2,127.9,140.6,141.6,159.0$, 164.8.

2,4,6-tris(9-Ethyl-9H-carbazol-3-yl)pyrimidine (2c). The title compound was obtained according to the general procedure and purified by column chromatography $\left(\mathrm{SiO}_{2}\right.$, AcOEt/petroleum ether, 3:7) followed by recrystallization from $\mathrm{CH}_{2} \mathrm{Cl}_{2} / n$-heptane. Pale yellow solid. Yield: $51 \%$ (330 mg). Mp: $176-177{ }^{\circ} \mathrm{C} .{ }^{1} \mathrm{H}-\mathrm{NMR}\left(300 \mathrm{MHz}, \mathrm{CDCl}_{3}\right): \delta$ $1.52(\mathrm{t}, 9 \mathrm{H}, J=6.3 \mathrm{~Hz}), 4.46(\mathrm{q}, 6 \mathrm{H}, J=7.2 \mathrm{~Hz}), 7.37-7.33(\mathrm{~m}, 3 \mathrm{H}), 7.62-7.47(\mathrm{~m}, 9 \mathrm{H}), 8.22(\mathrm{~d}, 1 \mathrm{H}, J=2.4 \mathrm{~Hz})$, 8.38-8.33 (m, 3H), $8.59(2 \mathrm{H}, \mathrm{d}, J=8.7 \mathrm{~Hz}), 9.04\left(1 \mathrm{H}, \mathrm{dd}, J_{1}=8.7 \mathrm{~Hz}, J_{2}=1.2 \mathrm{~Hz}\right), 9.14(\mathrm{~s}, 2 \mathrm{H}), 9.59(\mathrm{~s}, 1 \mathrm{H}) .{ }^{13} \mathrm{C}-$ NMR $\left(75 \mathrm{MHz}, \mathrm{CDCl}_{3}\right)$ : $\delta$ 13.9, 37.8, 108.2, 108.7, 108.8, 119.2, 119.4, 119.8, 120.8, 120.9, 121.2, 123.2, 123.4, 123.5, 123.8, 125.4, 125.7, 126.1, 126.8, 129.1, 130.0, 140.6, 141.6. HRMS (ESI/ASAP), $\mathrm{m} / \mathrm{z}$ calculated for $\mathrm{C}_{46} \mathrm{H}_{38} \mathrm{~N}_{5}[\mathrm{M}+\mathrm{H}]^{+} 660.3122$, found 660.3122 .

\section{Conclusions}

Push-pull pyrimidines substituted with a different number of either triphenylamine or 9-ethylcarbazole groups were prepared by Suzuki cross-coupling reaction from the corresponding chloropyrimidines and boronic acids. The molecules presented absorption wavelengths in the UV region and emitted violet-blue light in dichloromethane solution with a higher fluorescence quantum yield and a stronger ICT observed for the triphenylamine derivatives. The addition of acid was accompanied by a dramatic quenching of the fluorescence except for the 9-ethylcarbazole derivatives $\mathbf{2 b}$ and $\mathbf{2 c}$ (and partially for $\mathbf{1 b}$ ). In these cases, protonation led to the progressive disappearance of the emission band and the appearance of a new red-shifted complementary emitting band. Thus, white photoluminescence could be obtained by controlled protonation. White emission was also achieved in solid state. 


\section{References}

1. Nicolai, H. T.; Hof, A. J.; Blom, P. W. M., Charge transport in white light-emitting polymers. Organic Optoelectronics and Photonics li 2006, 6192.

2. Lee, P. I.; Hsu, S. L. C.; Lee, R. F., White-light-emitting diodes from single polymer systems based on polyfluorene copolymers end-capped with a dye. Polymer 2007, 48, 110-115.

3. Niu, Y. H.; Liu, M. S.; Ka, J. W.; Bardeker, J.; Zin, M. T.; Schofield, R.; Chi, Y.; Jen, A. K. Y., Crosslinkable holetransport layer on conducting polymer for high-efficiency white polymer light-emitting diodes. Adv Mater 2007, 19, 300+ .

4. Liedtke, A.; O'Neill, M.; Wertmoller, A.; Kitney, S. P.; Kelly, S. M., White-light oleds using liquid crystal polymer networks. Chem Mater 2008, 20, 3579-3586.

5. Lee, P. I.; Hsu, S. L. C.; Lin, P. Y., White-light-emitting diodes from single polymer systems based on polyfluorene copolymers with quinoxaline derivatives. Macromolecules 2010, 43, 8051-8057.

6. Madhwal, D.; Rait, S. S.; Kumar, A.; Verma, A.; Tada, K.; Onoda, M.; Bhatnagar, P. K.; Mathur, P. C., Development and characterization of an efficient bio-white polymer light-emitting diode with red and green phosphorescent dyes as dopants. J Mater Sci 2010, 45, 3300-3303.

7. Lee, H. K.; Kim, T. H.; Park, J. H.; Kim, J. K.; Park, O. O., White-light-emitting diodes using miscible polymer blend doped with phosphorescent dye. Org Electron 2011, 12, 891-896.

8. Meng, L. C.; Lou, Z. D.; Yang, S. Y.; Hou, Y. B.; Teng, F.; Liu, X. J.; Li, Y. B., White organic light-emitting diodes based on a combined electromer and monomer emission in doubly-doped polymers. Chinese Phys B 2012, 21.

9. Nicolai, H. T.; Hof, A.; Blom, P. W. M., Device physics of white polymer light-emitting diodes. Adv Funct Mater 2012, 22, 2040-2047.

10. Kuo, C. P.; Chuang, C. N.; Chang, C. L.; Leung, M. K.; Lian, H. Y.; Wu, K. C. W., White-light electrofluorescence switching from electrochemically convertible yellow and blue fluorescent conjugated polymers. J Mater Chem C 2013, 1, 2121-2130.

11. Liu, B. X.; Liu, Q. Q.; Tong, C. Y.; Lu, X. D.; Lu, C. L., Blue-light-emitting surface-functionalized zns nanoparticles and their transparent polymer nanocomposites with near-white light emission. Colloid Surface A 2013, 434, 213-219.

12. Leong-Hoi, A.; Claveau, R.; Flury, M.; Uhring, W.; Serio, B.; Anstotz, F.; Montgomery, P. C., Detection of defects in a transparent polymer with high resolution tomography using white light scanning interferometry and noise reduction. Proc Spie 2015, 9528.

13. Nam, G. H.; Park, I. K., Cdse quantum dot-conducting polymer hybrid structure for phosphor-free white light-emitting diodes. J Korean Phys Soc 2015, 66, 785-789.

14. Niu, W. Y.; Sun, J. W.; Yan, P. F.; Li, Y. X.; An, G. H.; Li, G. M., 2d I-di-toluoyl-tartaric acid lanthanide coordination polymers: Toward single-component white-light and nir luminescent materials. Chem-Asian J 2016, 11, 555-560.

15. Lee, J. S.; Kang, B. H.; Kim, S. H.; Lee, J. W.; Lee, S. W.; Kim, S. W.; Gopalan, S. A.; Kwon, J. B.; Bae, J. H.; Kim, E. S.; Kwon, D. H.; Kang, S. W., All-solution-processed high-brightness hybrid white quantum-dot light-emitting devices 
utilizing polymer modified quantum dots. Org Electron 2017, 42, 393-398.

16. Li, B. N.; Liu, L.; Fu, G. R.; Zhang, Z.; Li, H. Y.; Lu, X.; Wong, W. K.; Jones, R. A., Color-tunable to direct white-light and application for white polymer light emitting diode (wpled) of organo-eu3+- and organo-tb3+-doping polymer. J Lumin 2017, 192, 1089-1095.

17. Tian, L. L.; Zhang, W.; Yang, B.; Lu, P.; Zhang, M.; Lu, D.; Ma, Y. G.; Shen, J. C., Zinc(ii)-induced color-tunable fluorescence emission in the pi-conjugated polymers composed of the bipyridine unit: A way to get white-light emission. J Phys Chem B 2005, 109, 6944-6947.

18. Zhen, H. Y.; Xu, W.; King, W.; Chen, Q. L.; Xu, Y. H.; Jiang, J. X.; Peng, J. B.; Cao, Y., White-light emission from a single polymer with singlet and triplet chromophores on the backbone. Macromol Rapid Comm 2006, 27, 2095-2100.

19. Tang, K. C.; Tseng, S. R.; Li, W. S.; Meng, H. F.; Horng, S. F.; Hsu, C. S., Broad band and white phosphorescent polymer light-emitting diodes in multilayer structure. Synthetic Met 2008, 158, 287-291.

20. Zhang, Y. F.; Xu, Z.; Zhang, F. J.; Wang, Y.; Zhao, S. L., White organic light emitting device with dyestuff dcjtb mended in polymer. Spectrosc Spect Anal 2008, 28, 760-762.

21. Wang, R.; Peng, J.; Qiu, F.; Yang, Y. L.; Xie, Z. Y., Simultaneous blue, green, and red emission from diblock copolymer micellar films: A new approach to white-light emission. Chem Commun 2009, 6723-6725.

22. Zhang, T. H.; Gong, Z. C.; Que, L., A white-light source operated polymer-based micromachined fabry-perot chemo/biosensor. 2009 4th leee International Conference on Nano/Micro Engineered and Molecular Systems, Vols 1 and 2 2009, 181-184.

23. Wang, R.; Peng, J.; Qu, F.; Yang, Y. L., Enhanced white-light emission from multiple fluorophores encapsulated in a single layer of diblock copolymer micelles. Chem Commun 2011, 47, 2787-2789

24. Watanabe, K.; Sakamoto, T.; Taguchi, M.; Fujiki, M.; Nakano, T., A chiral pi-stacked vinyl polymer emitting white circularly polarized light. Chem Commun 2011, 47, 10996-10998.

25. Willander, M.; Nur, O.; Zaman, S.; Zainelabdin, A.; Bano, N.; Hussain, I., Zinc oxide nanorods/polymer hybrid heterojunctions for white light emitting diodes. J Phys D Appl Phys 2011, 44.

26. Wang, B. Z.; Zhang, X. P.; Liu, H. M., White-light-emitting diode based on a single-layer polymer. Aip Adv 2013, 3.

27. Wang, Z. W.; Gao, D. Z.; Ma, X. J.; Meng, J., White-light interferometry for measuring fuel pressure in icf polymermicrosphere targets. Fusion Sci Technol 2014, 66, 432-437.

28. Sun, C.; Zhang, Y.; Sun, K.; Reckmeier, C.; Zhang, T. Q.; Zhang, X. Y.; Zhao, J.; Wu, C. F.; Yu, W. W.; Rogach, A. L., Combination of carbon dot and polymer dot phosphors for white light-emitting diodes. Nanoscale 2015, 7, 1204512050.

29. Taudt, C.; Baselt, T.; Oreski, G.; Hirschl, C.; Koch, E.; Hartmann, P., Cross-linking characterization of polymers based on their optical dispersion utilizing a white-light interferometer. Proc Spie 2015, 9525.

30. Chen, S. A.; Chang, E. C.; Chuang, K. R.; Chao, C. I.; Wei, P. K.; Fann, W. S., Conjugated polymer blends as emitting layer for white light led. Abstr Pap Am Chem S 1998, 215, U392-U392. 
31. Goustouridis, D.; Manoli, K.; Chatzandroulis, S.; Sanopoulou, M.; Raptis, I., Characterization of polymer layers for silicon micromachined bilayer chemical sensors using white light interferometry. Sensor Actuat B-Chem 2005, 111, 549554.

32. Huang, J. S.; Li, G.; Wu, E.; Xu, Q. F.; Yang, Y., Achieving high-efficiency polymer white-light-emitting devices. Adv Mater 2006, 18, 114-117.

33. Kassamakov, I.; Ojala, K.; Salmia, A.; Haeggstrom, E.; Aaltonen, J.; Huber, A.; Saarikko, H.; Osterberg, M.; Oinonen, M., Characterization of dents and grooves on polymer films using scanning white light interferometry. Optical Micro- and Nanometrology in Microsystems Technology 2006, 6188.

34. Kim, T. H.; Lee, H. K.; Park, O. O.; Chin, B. D.; Lee, S. H.; Kim, J. K., White-light-emitting diodes based on iridium complexes via efficient energy transfer from a conjugated polymer. Adv Funct Mater 2006, 16, 611-617.

35. Chuang, C. Y.; Shih, P. I.; Chien, C. H.; Wu, F. I.; Shu, C. F., Bright-white light-emitting devices based on a single polymer exhibiting simultaneous blue, green, and red emissions. Macromolecules 2007, 40, 247-252.

36. Park, J. J.; Park, T. J.; Jeon, W. S.; Kim, S. Y.; Lee, Y. K.; Jang, J.; Kwon, J. H., White polymeric light-emitting diodes based on doping of an orange ir complex in a fluorene blue polymer. Idw '07: Proceedings of the 14th International Display Workshops, Vols 1-3 2007, 1033-1036.

37. Chitara, B.; Bhat, S. V.; Vivekchand, S. R. C.; Gomathi, A.; Rao, C. N. R., White-light sources based on composites of gan nanocrystals with conducting polymers and nanophosphors. Solid State Commun 2008, 147, 409-413.

38. Inoue, A.; Hosokawa, T.; Haishi, M.; Ohtani, N., 4-(dicyanomethylene)-2-methyl-6-(p-dimethylaminostyryl)-4h-pyran $(\mathrm{dcm})$-doping density dependence of luminescence spectra and white emission in polymer light-emitting diodes. Physica Status Solidi C - Current Topics in Solid State Physics, Vol 6, No 1 2009, 6, 334-337.

39. Jeon, S. O.; Joo, C. W.; Yook, K.; Lee, J. Y., Color control of multilayer stacked white polymer light-emitting diodes using a quantum dot as an interlayer. Appl Phys Lett 2009, 94.

40. Park, J. J.; Park, T. J.; Jeon, W. S.; Kim, S. Y.; Lee, Y. K.; Jang, J.; Kwon, J. H., White polymeric light-emitting diodes based on doping of an orange ir complex in a fluorene blue polymer host. Mol Cryst Liq Cryst 2009, 498, 290-297.

41. Cheng, G.; Fei, T.; Zhao, Y.; Ma, Y. G.; Liu, S. Y., White phosphorescent polymer light-emitting devices based on a wide band-gap polymer derived from 3,6-carbazole and tetraphenylsilane. Org Electron 2010, 11, 498-502.

42. Kim, S. H.; Jin, Y.; Yu, J. Y.; Kim, J.; Song, S.; Suh, H.; Lee, K., Color stable white polymer light-emitting diodes with single emission layer. Synthetic Met 2010, 160, 835-838.

43. Hu, B.; Yao, C.; Huang, X. R., Designing of the white-light emission from a single-polymer system: Quantum theoretical study. Polym Sci Ser a+ 2011, 53, 1097-1105.

44. Jeon, Y. P.; Choo, D. C.; Kim, T. W., Color tunable white organic light-emitting devices with a hybrid 2-methyl-9,10di(2-naphthyl)anthracene small molecule/poly(2-methoxy-5-(2-ethyhexoxy)-1,4-phenylenevinylene) polymer emitting layer. Thin Solid Films 2012, 521, 189-192.

45. Kim, J. H.; Song, W. S.; Yang, H., Color-converting bilayered composite plate of quantum-dot-polymer for high-color 
rendering white light-emitting diode. Opt Lett 2013, 38, 2885-2888.

46. Feng, C.; Sun, J. W.; Yan, P. F.; Li, Y. X.; Liu, T. Q.; Sun, Q. Y.; Li, G. M., Color-tunable and white-light emission of one-dimensional I-di-2-thenoyltartaric acid mixed-lanthanide coordination polymers. Dalton T 2015, 44, 4640-4647.

47. He, D. F.; Tang, Q.; Liu, S. M.; Luo, F.; Liu, Y. W.; Li, N.; Miao, J.; Wang, X. Q.; Chen, X. G.; Ma, F. J.; Liu, S. X., White-light emission by selectively encapsulating single lanthanide metal ions into alkaline earth metal-organic coordination polymers. Dyes Pigments 2015, 122, 317-323.

48. da Silva, M. A. T.; Thomazini, E. F.; Albertini, M.; Renzi, W.; Franchello, F.; Dias, I. F. L.; Duarte, J. L.; Pocas, L. C.; Lourenco, S. A., Characterization of digital textile printing and polymer blend (pfo-dmp:P3ht) for application in manufacture of organic diodes emitting white light - woleds. Opt Mater 2016, 62, 119-131.

49. Fan, L. M.; Fan, W. L.; Li, B.; Zhao, X.; Zhang, X. T., W-shaped 1,3-di(2,4-dicarboxyphenyl)benzene based lanthanide coordination polymers with tunable white light emission. New J Chem 2016, 40, 10440-10446.

50. Kim, Y. J.; Park, B. C.; Park, J.; Kim, H. D.; Kim, N. H.; Suh, Y. D.; Kim, Y. K., White-light-emitting magnetite nanoparticle-polymer composites: Photonic reactions of magnetic multi-granule nanoclusters as photothermal agents. Nanoscale 2016, 8, 17136-17140. 